Li et al., Afr J Tradit Complement Altern Med. (2017) 14 (4): 180-187

https://doi.org/10.21010/ajtcam.v14i4.21

\title{
ARISTOLOCHIA BRACTEOLATE RETZ. ATTENUATES HYPERURICEMIA IN A METABOLIC ARTHRITIS RAT MODEL
}

\author{
Yun-peng Li ${ }^{1}$, Shuang Wu${ }^{1}$, Afou Ran ${ }^{1}$, Da-yong Xu' ${ }^{1}$, Jing-mei Wei ${ }^{1}$, Zi-long Zhao ${ }^{2 *}$ \\ ${ }^{1}$ Department of Spine, Henan Province Hospital of Traditional Chinese Medicine, Zhengzhou, Henan, 450002, \\ China \\ ${ }^{2}$ Department of Pediatric Orthopedics, Luoyang Orthopedictraumatological Hospital, Luoyang, Henan, 471000, \\ China
}

Corresponding author Email: zhaozilongqq@ hotmail.com

\begin{abstract}
Background: The leaves of Aristolochia bracteolata Retz. has been documented in the folk medicine literature for its antiarthritic activity. The target of the research envisaged was to elucidate the activity of A. bracteolata extract on hyperuricemic condition in arthritis rat model.

Materials and Methods: Dried and powdered plant leaves were extracted using ether and chloroform. Potassium oxonate was injected intra-articularly to produce arthritis. The hyperuricemic effect, of A. bracteolate was analyzed by studying levels of uric acid in serum as well as in urine of arthritis induced rats. Effects of plant extracts were also studied on BUN (blood urea nitrogen) levels and fraction of uric acid excreted.

Results: Results indicate that administration of $A$. bracteolata presented substantial change in uric acid concentration, augmented by potassium oxonate administration in rats. The reduction in levels of uric acid levels was nearly same as allopurinol. The investigation also revealed that the primary plant extract has nephroprotective effect by enhancing the production of Prostaglandin $\mathrm{E}_{2}$ and Interleukin-1. Histological studies of rat kidney slices indicated the safety of the present plant extract.

Conclusion: The crude extract of $A$. bracteolate can be used to reduce hyperuricemia in metabolic arthritis produced in rat model, without inducing any potential damaging effects.
\end{abstract}

Key words: Hyperuricemia, Aristolochia bracteolate, arthritis, rat model

\section{Introduction}

Acute arthritis is characterized with inflammation in tenderized swollen joints. It is induced by raised levels of blood uric acid, which are banked in bone joints and tendons, and subsequently in the surrounding tissues. Uric acid is developed due to oxidation of hypoxanthine and xanthine, catalyzed by xanthine oxidase. In majority of cases, renal insufficiency, leading to uric acid accumulation, is the driving force for causing hyperuricemia. Factors worsening the arthritic condition include surplus activeness of xanthine oxidase (XOD) and reduced excrement of uric acid (Wortmann, 2002; Zhou et al., 2006). Prolonged nephritis, renal dysfunction and metabolic syndromes are the subsequent perpetual effects of hyperuricemic patients. (Iseki et al., 2001; Iseki et al.,2004; Ishizaka, 2005; Yoo et al., 2005; Cirillo et al., 2006; Zhou et al., 2006; Weiner et al., 2008)

Out of a large number of various synthetic and herbal anti-hyperuricemic agents available in market, mainly from the class of uricosuric agents and XOD inhibitors, suffer from development of adverse effects including gastric irritation, suppression of bone marrow and nephrotoxicity. (Hammer et al., 2001; Horiuchi et al., 2000; Terkeltaub, 2003; Schlesinger, 2004) When such drugs fail the patient may turn-up to allopurinol, a drug of choice for arthritis, but with significant hypersensitivity reactions. Therefore, there is a strong need to explore safe and potent drugs for treatment of hyperuricemia.

Research was envisaged under an impression to explore activity of Aristolochia bracteolate Retz. as a potential candidate that could attenuate hyperuricemia in arthritic rat model probably due to its anti-oxidative effects owing to presence of phenolic components, such as phenolic diterpenes and acids, and various flavonoids. Literature reveals that the Aristolochiaceae family includes more than 400 species and 7 genera's, which have profound contents of aristolochic acid derivatives and various flavonoids. The plant leaves are known to bear antioxidant activity through free radical scavenging effect (Shirwaikar et al., 2003). The plant leaves even have wound healing activity through modulation of two enzymes - 
Li et al., Afr J Tradit Complement Altern Med. (2017) 14 (4): 180-187

https://doi.org/10.21010/ajtcam.v14i4.21

super oxide dismutase and catalase. The excessively bitter plant leaves are also known to own anti-inflammatory and anthelmintic activity (Kavitha et al., 2009).

All the above findings, indicated that no research on anti-hyperuricemic activity of A. bracteolate has been investigated. Hence the present work was envisaged to find the activity of various A. bracteolate extracts on serum and urine levels of uric acid and creatinine, BUN levels, fraction of uric acid excreted, XOD activity and protective levels of $\mathrm{PGE}_{2}$ and IL-1

\section{Materials and Methods Animals}

Sprague-Dawley rats (male), weighing around 80-200 g, procured from the Institutional Laboratory Animal Center, were allowed to reside for seven days in metabolic cages to accommodate with the environment prior before being used for further experiments. All the animals were retained on standard environmental conditions with temperature $25 \pm$ $1^{\circ} \mathrm{C}$ and a $12 \mathrm{hr}$ light and $12 \mathrm{hr}$ dark cycle with liberal approach to food as well as water for the entire span of study. The animal maintenance and proposed experimentation were executed with relevance to norms set by Provision and General Recommendation of Chinese Experimental Animals Administration Legislation, Institutional Committee.

\section{Drugs and chemicals}

Aristolochia bracteolata leaves were procured from authorized supplier and identified using literature provided. All the chemicals of analytical grade were used. Petroleum ether, ethanol, ethylacetate, chloroform and acetone were procured from Nanjing Hanbang Chemical Reagent Company (Nanjing, PR China). Allopurinol, XOD and potassium oxonate were purchased from Sigma Aldrich (USA). From the local laboratory chemical suppliers, authentic kits for quantification of biochemical markers such as uric acid, BUN and creatinine were brought. All other chemicals used were of analytical grade and purchased from Sigma (USA).

\section{Preparation of plant extracts}

Dried and pulverized stems of A. bracteolata were macerated in a mixture of petroleum ether and methanol for 6 days, and was subjected to filtration. The filtrate was subjected to spray drying at a temperature of $40^{\circ} \mathrm{C}$ to obtain powder weighing around $1145 \mathrm{~g}$. This spray dried fluffy powder was stored in desiccator, to avoid moisture absorption, for further use. The spray dried fluffy powder was extracted 3 times with equal volumes $(8.7 \mathrm{~L})$ of chloroform, acetone, ethyl acetate and ethyl alcohol. Each fraction was subjected to low temperature evaporation under vacuum to obtain respective chloroform fraction (FC, 136g, 12\%), acetone fraction (FA, 234g, 20\%), ethanol fraction (FE, 459g, 40\%) and ethyl acetate fraction (FAE, 317, 28\%).

\section{Induction of hyperuricemia in rat and drug extract administration}

Randomly seven groups of ten rat each were allotted for triggering hyperuricemia. As documented, the rats were treated with a uricase inhibitor, potassium oxonate, for inducing hyperuricemia. (Stavric et al., 1975; Zhu et al., 2004; Nguyen et al., 2005) Rats were injected intraperitoneally with potassium oxonate $(250 \mathrm{mg} / \mathrm{kg})$ to elevate the levels of serum uric acid, and after one hour administered orally with vehicle, drug extracts (FC-120 mg/kg, FA-200 mg/kg, FE-400 mg/kg and FAE-280mg/kg) and allopurinol, a xanthine oxidase inhibitor (10 mg/kg). One group was a positive control group which did not received any anti-hyperuricemic drug or extract. The extracts were dissolved in aqueous solution of $0.25 \%$ carboxymethyl cellulose sodium before administration. The dose of extracts was once a day during afternoon at $12.00-$ $1.00 \mathrm{pm}$ given by oral route for 4 days. Before drug administration, only water not food was withdrawn for 1 hour.

\section{Collection of blood, urine and organ samples}

Blood samples from experimental rats were derived after 2 hours of drug administration, from vein of the tail. The blood samples were left to clot for around 1 hour at room temperature. These clotted blood aliquots were assembled and subjected to centrifugation for 10 minutes at $1200 \times g$ for serum separation. Using commercial detection kits, concentrations of uric acid, creatinine and urea were quantified in $\mathrm{mg} / \mathrm{dL}$, and allopurinol administered rat levels were considered as positive control. 24 hours prior to sacrificing the animals, the urine samples were collected for determination of uric acid, creatinine and urea. From the sacrificed animals the livers were dissected and immediately cryopreserved for XOD assay. 
Li et al., Afr J Tradit Complement Altern Med. (2017) 14 (4): 180-187

https://doi.org/10.21010/ajtcam.v14i4.21

\section{Assay of blood urea nitrogen, creatinine and uric acid}

The levels of serum uric acid $\left(S_{u}\right)$, serum creatinine $\left(S_{c}\right)$, urinary uric acid $\left(U_{u}\right)$, Urinary creatinine $\left(U_{c}\right)$ and blood urea nitrogen (BUN) were quantified using standard commercial diagnostic kits. The assays were performed in triplicate. The fractional excretion of uric acid (FEUA) was figured to evaluate the uricosuric effect of test samples according to the procedure reported elsewhere. (Perez-Ruiz et al., 2002)

\section{Assay involving xanthine oxidase activity}

The study was performed on the rat liver as reported in literature (Mo et al., 2007). The rat liver was introduced into a tissue homogenizer and run for 40 minutes with sodium pyrophosphate buffer of $\mathrm{pH}$ 7.4. The crushed product was subjected to centrifugation at $4000 \times g$ for around 10 minutes and the supernatant layer was utilized for the assay. The XOD activity was quantified in potassium phosphate buffer $(50 \mathrm{mM} ; \mathrm{pH} 10)$ composing disodium EDTA (disodium salt of diamine tetraacetic acid; $1 \mathrm{mM})$ in the presence of substrate xanthine $(100 \mathrm{mM})$. After incubation for around 30 minutes at $37^{\circ} \mathrm{C}$, the process was ceased by addition of $0.5 \mathrm{~mL}$ of $0.5 \mathrm{M} \mathrm{HCl}$. Uric acid production was determined by UV absorbance in a spectrophotometer at wavelength $290 \mathrm{~nm}$. The protein content was calculated by Bradford method against standard bovine serum albumin.

\section{Renal assay of PGE 2 and IL-1}

The rat kidneys were crushed in a tissue homogenizer in Tris- $\mathrm{HCl}$ buffer maintained at $4^{\circ} \mathrm{C}$ containing $12 \mathrm{mg} / \mathrm{ml}$ of indomethacin, which ensured inhibition of $\mathrm{PGE}_{2}$ and IL-2 from being synthesized further. The proteins were separated by high speed centrifugation at $12000 \times g$. All the operations were performed at $4^{\circ} \mathrm{C}$. The collected supernatant was preserved at $-80^{\circ} \mathrm{C}$ for further use. The fraction of $\mathrm{PGE}_{2}$ and IL-2 was determined using ELISA kit (Molecular Devices), with measurement of absorbance at $450 \mathrm{~nm}$. The threshold limit for detection of IL-1 was $20 \mathrm{mg} / \mathrm{mL}$ with coefficient of variation less than $5 \%$.

\section{Determination of transforming growth factor - $\beta 1$ (TGF- $\beta 1$ ) and connective tissue growth factor (CTGF) levels}

Kidneys embedded in paraffin were sliced with a thickness of $3 \mu \mathrm{m}$ using a microtome. These sections were washed to remove paraffin subsequently avoiding dehydration. The tissue sections were satiated in presence of monoclonal antibodies of anti- TGF- $\beta 1$ (BioVision) and anti-CTGF (BioWorld). The sections were rinsed with polyphosphate buffer and incubated with biotinylated rabbit anti-mouse $\operatorname{IgG}(1: 400$, MaiXin Bio). Finally, the thin section was treated with diaminobenzidine (MaxVision) and a counterstain - heamotoxylin. Computerized morphometry with the help of Image Pro Plus (Version 5.1), was carried to explore TGF- $\beta 1$ and CTGF count through their interstitial presence. Magnification of $\times 200$ was use to quantify 20 randomly selected areas in the cortex of the kidney specimen. The values were indicated as percentage of the total measured area.

\section{Statistical representation}

All the resulting values are expressed as mean \pm S.E.M, employing Origin software version 6.1 and GraphPad software version 5.0. SPSS 13.0 was employed to carry out Two-tailed Student's t-test and ANOVA, wherever appropriate, where the p-values more than 0.05 were regarded insignificant.

\section{Results}

The data indicated in Table 1 showed that A. bracteolata extracts reduced the levels of $\mathrm{S}_{\mathrm{u}}(\mathrm{p}<0.05, \mathrm{p}<0.01$ and $\mathrm{p}<0.001)$ and $\mathrm{S}_{\mathrm{c}}(\mathrm{p}<0.05, \mathrm{p}<0.05$ and $\mathrm{p}<0.001)$ in the order FEA $<\mathrm{FE}<\mathrm{FC}<\mathrm{FA}$. The $\mathrm{U}_{\mathrm{u}}$ levels $(\mathrm{p}<0.05, \mathrm{p}<0.01$ and $\mathrm{p}<0.001)$ and $\mathrm{U}_{\mathrm{c}}$ levels $(\mathrm{p}<0.01, \mathrm{p}<0.01$ and $\mathrm{p}<0.001)$ were elevated in the order $\mathrm{FA}<\mathrm{FC}<\mathrm{FE}<\mathrm{FEA}$ on hyperuricemic rats. The BUN levels $(p<0.05, p<0.05$ and $p<0.001)$ levels were also reversed compared to positive untreated rats. Being a standard, allopurinol modulated the levels of $\mathrm{S}_{\mathrm{u}}(\mathrm{p}<0.001), \mathrm{S}_{\mathrm{c}}(\mathrm{p}<0.001), \mathrm{U}_{\mathrm{u}}$ levels $(\mathrm{p}<0.001), \mathrm{U}_{\mathrm{c}}$ levels $(\mathrm{p}<0.001)$ and BUN levels $(\mathrm{p}<0.001)$. 
Li et al., Afr J Tradit Complement Altern Med. (2017) 14 (4): 180-187

https://doi.org/10.21010/ajtcam.v14i4.21

Table 1: PC, positive control; Alp, Allupurinol; FC, chloroform fraction; FA, acetone fraction; FEA, ethyl acetate fraction; FE, ethanol fraction.

\begin{tabular}{|c|c|c|c|c|c|c|c|c|}
\hline Group & $\begin{array}{l}\text { Dose } \\
\text { (in } \\
\mathrm{mg} / \mathrm{kg} \text { ) }\end{array}$ & $\begin{array}{l}\text { Urine } \\
\text { volume } \\
\text { (ml/24 } \\
\text { hours) } \\
\end{array}$ & $\begin{array}{l}\mathrm{S}_{\mathrm{u}} \text { (in } \\
\mathrm{mg} / \mathrm{dL})\end{array}$ & $\begin{array}{l}\mathrm{S}_{\mathrm{c}} \quad \text { (in } \\
\mathrm{mg} / \mathrm{dL} \text { ) }\end{array}$ & $\begin{array}{l}\mathrm{U}_{\mathrm{u}} \text { (in } \\
\mathrm{mg} / \mathrm{dL})\end{array}$ & $\begin{array}{l}\mathrm{U}_{\mathrm{c}} \\
(\mathrm{mg} / \mathrm{dL})\end{array}$ & $\begin{array}{l}\text { Fraction } \\
\text { excretion } \\
\text { of uric } \\
\text { acid }\end{array}$ & $\begin{array}{l}\mathrm{BUN} \text { (in } \\
\mathrm{mg} / \mathrm{dL})\end{array}$ \\
\hline Control & - & $\begin{array}{l}12.15 \\
1.22\end{array}$ & $\begin{array}{l}2.91 \\
0.08\end{array}$ & $\begin{array}{l}0.77 \\
0.03\end{array}$ & $\begin{array}{l}30.03 \\
2.87\end{array}$ & $\begin{array}{l}118.56 \\
5.48\end{array}$ & $\begin{array}{l}8.25 \\
0.39\end{array}$ & $\begin{array}{l}7.22 \\
0.96\end{array}$ \\
\hline PC & - & $\begin{array}{l}18.33 \\
1.04\end{array}$ & $\begin{array}{ll}3.60 & \pm \\
0.35^{\# \# \#}\end{array}$ & $\begin{array}{l}1.03 \\
0.02^{\# \#}\end{array}$ & $\begin{array}{l}19.13 \pm \\
1.93^{\# \# \#}\end{array}$ & $\begin{array}{l}80.36 \\
5.92^{\# \# \#}\end{array}$ & $\begin{array}{l}7.75 \\
0.48^{\#}\end{array}$ & $\begin{array}{l}10.22 \quad \pm \\
1.28^{\# \# \#}\end{array}$ \\
\hline Alp & 10 & $\begin{array}{l}14.92 \\
1.52\end{array}$ & $\begin{array}{ll}2.75 & \pm \\
0.25^{* * *} & \\
\end{array}$ & $\begin{array}{l}0.89 \quad \pm \\
0.06^{* * *}\end{array}$ & $\begin{array}{ll}28.52 & \pm \\
2.09^{* * *} & \\
\end{array}$ & $\begin{array}{l}89.33 \\
4.62^{* * *}\end{array}$ & $\begin{array}{l}10.14 \\
0.88^{* * *}\end{array}$ & $\begin{array}{ll}9.31 & \pm \\
1.02^{* * *} & \end{array}$ \\
\hline FC & 120 & $\begin{array}{l}17.66 \\
1.85^{* *}\end{array}$ & $\begin{array}{l}2.52 \\
0.36^{*}\end{array}$ & $\begin{array}{ll}0.72 & \pm \\
0.05^{*} & \end{array}$ & $\begin{array}{l}27.24 \\
1.94^{*}\end{array}$ & $\begin{array}{l}87.25 \\
5.98^{* *}\end{array}$ & $\begin{array}{ll}9.03 & \pm \\
0.72^{* *} & \end{array}$ & $\begin{array}{l}8.45 \\
1.28^{* *}\end{array}$ \\
\hline FA & 200 & $\begin{array}{l}15.42 \\
2.33^{* *}\end{array}$ & $\begin{array}{l}3.80 \\
0.15^{* *}\end{array}$ & $\begin{array}{ll}1.12 & \pm \\
0.07^{* *} & \\
\end{array}$ & $\begin{array}{l}18.88 \\
1.38^{* *}\end{array}$ & $\begin{array}{l}78.66 \\
6.04^{* *}\end{array}$ & $\begin{array}{ll}9.29 & \pm \\
0.36^{* *} & \\
\end{array}$ & $\begin{array}{l}8.52 \\
1.16^{* *}\end{array}$ \\
\hline FEA & 400 & $\begin{array}{ll}15.98 & \pm \\
1.87^{* * *} & \\
\end{array}$ & $\begin{array}{l}1.40 \\
0.28^{* * *} \\
\end{array}$ & $\begin{array}{ll}0.66 & \pm \\
0.02^{* * *} & \end{array}$ & $\begin{array}{l}33.19 \\
2.64^{* * *}\end{array}$ & $\begin{array}{l}121.87 \\
7.84^{* * *}\end{array}$ & $\begin{array}{ll}9.38 & \pm \\
0.83^{* * *} & \end{array}$ & $\begin{array}{l}8.68 \\
1.08^{* * *}\end{array}$ \\
\hline FE & 280 & $\begin{array}{ll}16.67 & \pm \\
2.02^{* *} & \\
\end{array}$ & $\begin{array}{l}2.48 \\
0.18^{* *} \\
\end{array}$ & $\begin{array}{ll}0.71 & \pm \\
0.04^{* * *} & \\
\end{array}$ & $\begin{array}{ll}32.62 & \pm \\
2.18^{* * *} & \\
\end{array}$ & $\begin{array}{l}120.29 \\
5.28^{* * *} \\
\end{array}$ & $\begin{array}{ll}8.66 & \pm \\
0.51^{\text {*** }} & \\
\end{array}$ & $\begin{array}{ll}8.02 & \pm \\
1.32^{* * *} & \\
\end{array}$ \\
\hline
\end{tabular}

Results indicating arithmatic mean \pm SEM, 10 rats in each group. The statistical analysis conducted using one-way ANOVA and Tukey-Kramer test. ${ }^{\#} \mathrm{p}<0.05,{ }^{\# \#} \mathrm{p}<0.01$ and ${ }^{\# \#} \mathrm{p}<0.001$, compared to control group. ${ }^{*} \mathrm{p}<0.05,{ }^{* *} \mathrm{p}<0.01$ and ${ }^{* * * *}$ $\mathrm{p}<0.001$ compared to positive control group.

The uric acid fraction excreted (FEUA) was slightly elevated after allopurinol administration $(\mathrm{p}<0.001)$ compared to FC extract $(\mathrm{p}<0.01)$. The urine volume was enhanced by allopurinol, $\mathrm{FC}(\mathrm{p}<0.01), \mathrm{FA}(\mathrm{p}<0.01), \mathrm{FEA}(\mathrm{p}<0.001)$ and FE $(\mathrm{p}<0.01)$ extracts compared to the control group. The volume of urine was comparatively more in positive control group. Induction of hyperuricemia with potassium oxonate remarkably potentiated the influence of XOD in rats $(\mathrm{p}<0.01)$, in comparison to the control group, as indicated in Fig. 1. Variable effects of plant extracts ware seen on the XOD activity, in the order FEA $(\mathrm{p}<0.01)<\mathrm{FE}(\mathrm{p}<0.01)<\mathrm{FC}(\mathrm{p}<0.01)<\mathrm{FA}(\mathrm{p}<0.01)$. Least XOD activity was achieved with FEA extract, but not as better as of allopurinol.

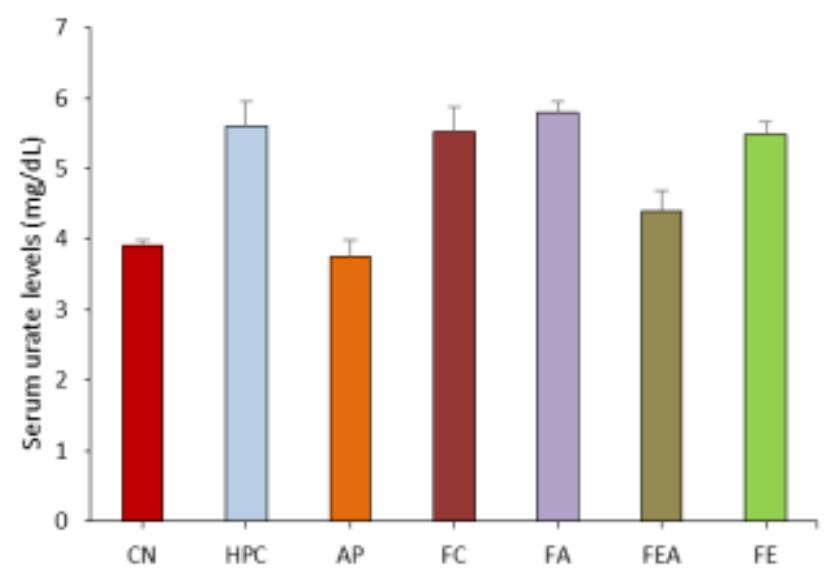

Figure 1: Comparative serum urate levels in control, hyperuricemic and plant extract treated rats. CN control group, HPChyperuricemic positive control, group, AP - Allopurinol treated, FC-Chloroform fraction treated, FA-Acetone fraction treated, FEA-Ethyl acetate fraction treated and FE-ethyl alcohol fraction treated.

The change in $\mathrm{PGE}_{2}$ and IL-1 are indicated in Fig. 2. PGE2 and IL-1 levels in hyperuricemic rats was more, which were significantly normalized by allopurinol. The plant extract fractions were capable of lowering the PGE $\mathrm{Pan}_{2}$ IL-1 levels, of which ethyl acetate fraction reversed the levels to values similar to allopurinol. 
Li et al., Afr J Tradit Complement Altern Med. (2017) 14 (4): 180-187

https://doi.org/10.21010/ajtcam.v14i4.21

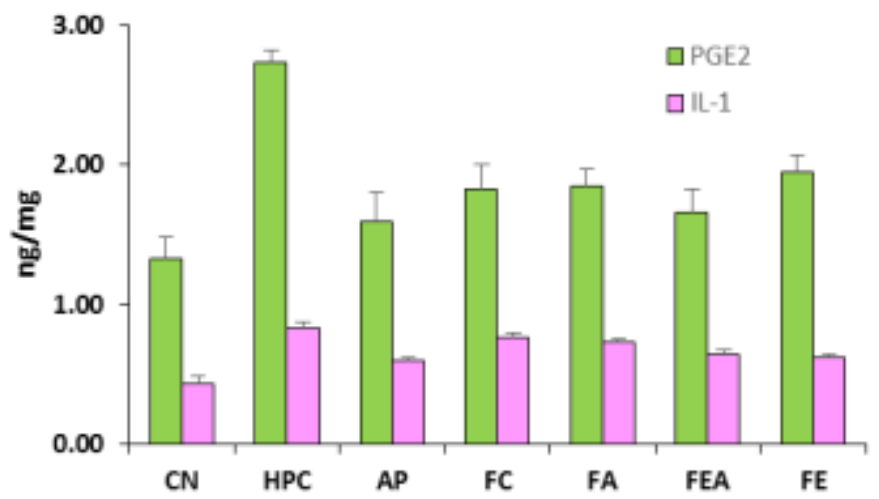

Figure 2: Comparative PGE2 and IL-1 levels in control, hyperuricemic and plant extract treated rats. CN control group, HPC- hyperuricemic positive control, group, AP - Allopurinol treated, FC-Chloroform fraction treated, FA-Acetone fraction treated, FEA-Ethyl acetate fraction treated and FE-ethyl alcohol fraction treated. The amount of PGE2 and IL2 was increased in rats after potassium oxonate and reversed variably by various A. bracteolata extracts fractions

Immunohistochemical studies of prepared specimen indicated TGF- $\beta 1$ and CTGF expression across the renal cell cytoplasm as well as in the cell membrane layers (supporting data provided in Fig. 3). Respective immunostained specimens indicated elevation in TGF- $\beta 1$ and CTGF levels compared to that of control group animals (Fig. 4 and Fig. 5).

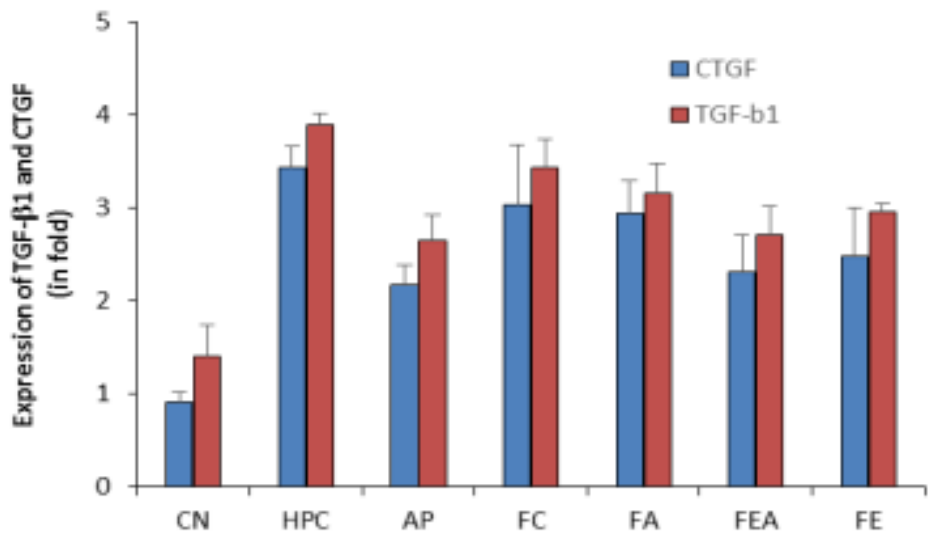

Figure 3: Comparative TGF- $\beta 1$ and CTGF levels in control, hyperuricemic and plant extract treated rats. CN control group, HPC- hyperuricemic positive control, group, AP - Allopurinol treated, FC-Chloroform fraction treated, FA-Acetone fraction treated, FEA-Ethyl acetate fraction treated and FE-ethyl alcohol fraction treated. The values are expressed as change in folds of the normal values.
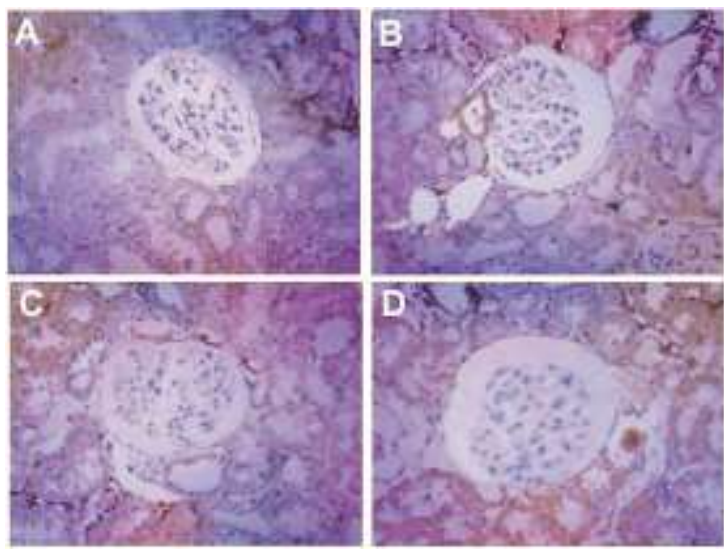

Figure 4: Representative micrographs indicating attenuated levels of TGF- $\beta 1$ in hyperuricemic rats. A. Control group, B. Positive control (Hyperuricemic rats), C. Allopurinol treated hyperuricemic rats, D. Hyperuricemic rats treated with primary extract of A. bracteolate 
Li et al., Afr J Tradit Complement Altern Med. (2017) 14 (4): 180-187

https://doi.org/10.21010/ajtcam.v14i4.21

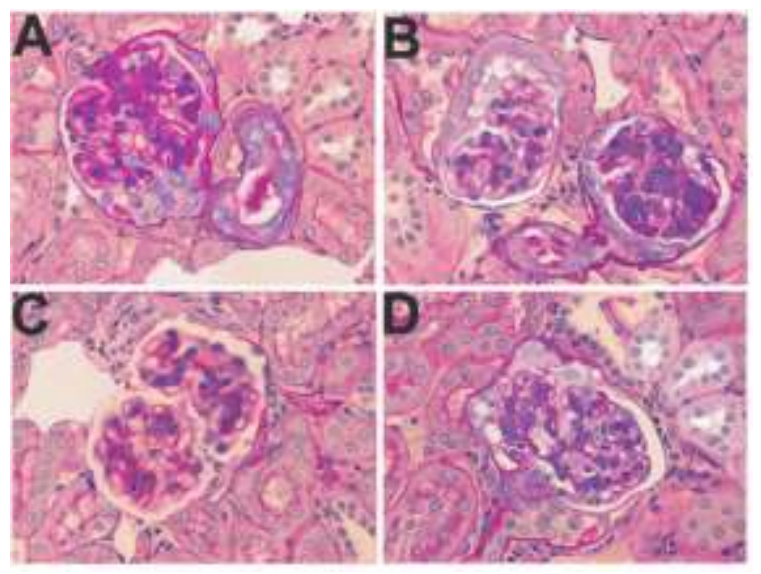

Figure 5: Representative micrographs indicating attenuated levels of CTGF in hyperuricemic rats. A. Control group, B. Positive control (Hyperuricemic rats), C. Allopurinol treated hyperuricemic rats, D. Hyperuricemic rats treated with primary extract of A. bracteolate

The histological studies were carried out as explained in above mentioned section. The micrographs indicated marked disappearance of brush border of epithelial cells. The potassium oxonate rats indicated reduction in renal tubular diameter as well as marked changes in the interstitial area. Allopurinol ameliorated tubulointerstitial pathologies to some extent during the span of treatment. Also minimal changes in tubular micrography was seen with various fractions of plant extracts, indicating its safety for kidneys (Fig. 6).

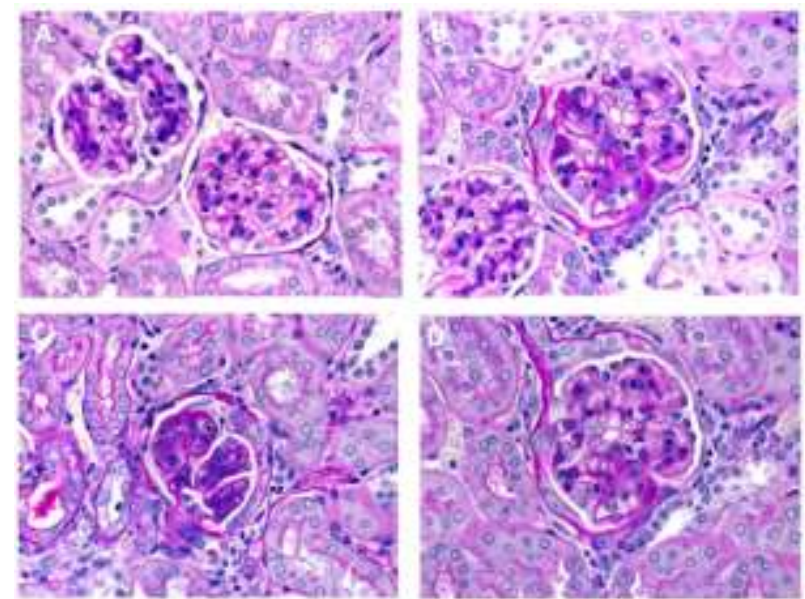

Figure 6: Histological micrographs of kidney slice of rats of different groups. A. Control group, B. Positive control (Hyperuricemic rats), C. Allopurinol treated hyperuricemic rats, D. Hyperuricemic rats treated with primary extract of A. bracteolate.

\section{Discussion}

Metabolic arthritis or gout may be considered a tragic stage of intense arthritis with symptoms including inflammatory and tenderized bloated joints. The symptoms may be a result of nepropathy characterized by tubulointerstitial fibrosis. Hyperuricemia is diagnosed in subjects that have a disturbed balance between uric acid production or abnormal purine metabolism and impaired elimination of uric acid. This elevated uric acid concentration in the serum above a normal range leads to gout. Hyperuricemia may be a common problem, but the treatments available are few, as termination of chemotherapeutic treatment may lead to relapse or worsening of the condition. Under such circumstances the patient has to rely on allopurinol, which may provoke hypertension. Thus natural products may be a good and potential alternative in medication of hyperuricemia. (Kong et al., 2002)

The present investigation was carried out using extracts of A. bracteolate, hyperuricemic rats induced with metabolic arthritis. Potassium oxonate, a uricase blocker has been used for developing hyperuricemia in rats. (Kong et al., 


\title{
Li et al., Afr J Tradit Complement Altern Med. (2017) 14 (4): 180-187
}

\author{
https://doi.org/10.21010/ajtcam.v14i4.21
}

2002) Owing to cost effectiveness and less time consuming, the present model may be considered an effective one as it can provide preliminary information about the possible capabilities of hyperuricemic activity of a model compound. Hence, anti-hyperuricemic activity of different plant extract fractions in comparison to Allupurinol, as a standard was evaluated. The evaluating parameters included $\mathrm{S}_{\mathrm{u}}, \mathrm{S}_{\mathrm{c}}, \mathrm{U}_{\mathrm{u}}, \mathrm{U}_{\mathrm{c}}, \mathrm{BUN}$ and XOD levels, and histopathological visualization of dissected kidneys after sacrificing the animals. The results indicated that $A$. bracteolate extract fractions significantly reduced the $\mathrm{S}_{\mathrm{u}}$ and $S_{\mathrm{c}}$ levels in potassium oxonate induced hyperuricemic rats. The $\mathrm{U}_{\mathrm{u}}$ levels were increased in comparison to allopurinol treated rats, whereas the $U_{c}$ levels were increased in the same context. Marked reversal in FEUA and BUN values was indicative that the A. bracteolate extracts are capable of increasing the fraction of urate excreted and also lower the blood urea nitrogen level.

It has been documented that in hyperuricemia, IL-1 is released which substantially triggers intercapillary cells and hastens injury of renal glomerulus coupled with inflammation. (Chen, 2006; Guan et al., 1998) Prostaglandin $\mathrm{E}_{2}\left(\mathrm{PGE}_{2}\right)$ is the most prominent lipid mediator for inducing pain coupled with inflammation in the tissues. (Narumiya et al., 1999) It is synthesized in the body as a result of cascade of biochemical reactions of IL-1 $1 \beta$. The effect of increased excretion levels of $\mathrm{U}_{\mathrm{u}}$ and fraction of uric acid excreted, may contribute to reduce the $\mathrm{PGE}_{2}$ and IL-1, subsequently enhancing the antiinflammatory effect of the plant extract fractions.

TGF- $\beta 1$ of a multifaceted polypeptide, well known for its fibrogenic effect and inflammatory action, for immunomodulation of cell and for control over turnover of extracellular matrix of kidney cells. Literature suggests loss of regulation of TGF- $\beta 1$ may lead to renal disorder. (Qi et al., 2008) In renal fibrosis CTGF and TGF- $\beta$ are known as key role players in profibrotic effect and variate growth of fibroblast cell. (Gupta et al., 2000) CTGF can promote TGF- $\beta$ effect in settings fibrotic mechanisms. (Okada, 2004) In view of the above reports, effects of A. bracteolate primary extract and allopurinol were studied on renal manifestation of TGF- $\beta 1$ and CTGF concentrations in rats with elevated levels of uric acid, triggered by potassium oxonate, and the observations were visualized by staining methods highlighting its immunohistochemistry. Studies carried in current research indicated that $A$. bracteolate ameliorates nephropathic effect by modulating TGF- $\beta 1$ and CTGF. The nephropathic effect was also supported by strong hyperuricemic effect produced by $A$. bracteolate extracts in various solvents system.

Moreover, the histological micrographs provided a background to ascertain that the A. bracteolate primary extracts are safe for the kidneys, as negligible damage to the interstitial linings and brush border of epithelial cells was marked. The micrographs can be regarded as an indication that no damage to the kidneys was occurred with the plant extracts.

Based on these findings, the A. bracteolate extracts ameliorate the hyperuricemia in metabolic arthritis rat model. However, a more detailed elucidation of A. bracteolata extracts and possible chemical constituents responsible for hyperuricemic effect is underway. Exploration of the said facts may even provide a deep insight for its possible nephroprotective role.

\section{References}

1. Chen C. (2006) MyD88-dependent IL-1 receptor signaling is essential for gouty inflammation stimulated by monosodium urate crystals. Journal of Clinical Investigation. 116(8):2262-2271.

2. Cirillo P, Sato W, Reungjui S, Heinig M, Gersch M, Sautin Y. (2006) Uric Acid, the Metabolic Syndrome, and Renal Disease. Journal of the American Society of Nephrology. 17(12 supplement 3): S165-S168.

3. Guan Z, Buckman S, Miller B, Springer L, Morrison A. (1998) Interleukin-1 -induced Cyclooxygenase-2 Expression Requires Activation of Both c-Jun NH2-terminal Kinase and p38 MAPK Signal Pathways in Rat Renal Mesangial Cells. Journal of Biological Chemistry. 273(44):28670-28676.

4. Gupta S, Clarkson M, Duggan J, Brady H. (2000) Connective tissue growth factor: Potential role in glomerulosclerosis and tubulointerstitial fibrosis. Kidney International. 58(4):1389-1399.

5. Hammer B, Link A, Wagner A, Böhm M. (2001) Hypersensitivitäts syndrom unter Therapie mit Allopurinol bei asymptomatischer Hyperurikämie mit tödlichem Ausgang. DMW - Deutsche Medizinische Wochenschrift. 126(47):1331-1334.

6. Horiuchi H, Ota M, Nishimura S, Kaneko H, Kasahara Y, Ohta T. (2000) Allopurinol induces renal toxicity by impairing pyrimidine metabolism in mice. Life Sciences. 66(21):2051-2070.

7. Iseki K, Ikemiya Y, Inoue T, Iseki C, Kinjo K, Takishita S. (2004) Significance of hyperuricemia as a risk factor for developing ESRD in a screened cohort. American Journal of Kidney Diseases. 44(4):642-650.

8. Iseki K, Oshiro S, Tozawa M, Iseki C, Ikemiya Y, Takishita S. (2001) Significance of Hyperuricemia on the Early Detection of Renal Failure in a Cohort of Screened Subjects. Hypertension Research. 24(6):691-697.

9. Ishizaka N. (2005) Association Between Serum Uric Acid, Metabolic Syndrome, and Carotid Atherosclerosis in Japanese Individuals. Arteriosclerosis, Thrombosis and Vascular Biology. 25(5):1038-1044. 
Li et al., Afr J Tradit Complement Altern Med. (2017) 14 (4): 180-187

https://doi.org/10.21010/ajtcam.v14i4.21

10. Kavitha D, Nirmaladevi R. (2009) Assessment of Aristolochia bracteolate leaf extracts for its biotherapeutic potential. African Journal of Biotechnology. 8(17):4242-4244.

11. Kong L, Zhou J, Wen Y, Li J, Cheng C. (2002) Aesculin Possesses Potent Hypouricemic Action in Rodents but is Devoid of Xanthine Oxidase/Dehydrogenase Inhibitory Activity. Planta med. 68(2):175-178.

12. Mo S, Zhou F, Lv Y, Hu Q, Zhang D, Kong L. (2007) Hypouricemic Action of Selected Flavonoids in Mice: Structure-Activity Relationships. Biol Pharm Bull. 30(8):1551-1556.

13. Narumiya S, Sugimoto Y, Ushikubi F. (1999) Prostanoid receptors: structures, properties, and functions. Physiol Rev., 79:1193-1226

14. Nguyen M, Awale S, Tezuka Y, Shi L, Zaidi S, Ueda J. (2005) Hypouricemic Effects of Acacetin and 4,5-ODicaffeoylquinic Acid Methyl Ester on Serum Uric Acid Levels in Potassium Oxonate-Pretreated Rats . Biological and Pharmaceutical Bulletin. 28(12):2231-2234.

15. Okada H. (2004) Connective Tissue Growth Factor Expressed in Tubular Epithelium Plays a Pivotal Role in Renal Fibrogenesis. Journal of the American Society of Nephrology. 16(1):133-143.

16. Perez-Ruiz F, Calabozo M, Erauskin G, Ruibal A, Herrero-Beites A. (2002) Renal underexcretion of uric acid is present in patients with apparent high urinary uric acid output. Arthritis \& Rheumatism. 47(6):610-613.

17. Qi W, Chen X, Poronnik P, Pollock C. (2008) Transforming growth factor- $\beta /$ connective tissue growth factor axis in the kidney. The International Journal of Biochemistry \& Cell Biology. 40(1):9-13.

18. Schlesinger N. (2004) Management of Acute and Chronic Gouty Arthritis. Drugs. 64(21):2399-2416.

19. Shirwaikar A, Somashekar A, Udupa A, Udupa S, Somashekar S. (2003) Wound healing studies of Aristolochia bracteolata Lam. with supportive action of antioxidant enzymes. Phytomedicine. 10(6-7):558-562.

20. Stavric B, Clayman S, Gadd R, Hébert D. (1975) Some in vivo effects in the rat induced by chlorprothixene and potassium oxonate. Pharmacological Research Communications. 7(2):117-124.

21. Terkeltaub R. (2003) Gout. New England Journal of Medicine. 349(17):1647-1655.

22. Weiner D, Tighiouart H, Elsayed E, Griffith J, Salem D, Levey A. (2008) Uric Acid and Incident Kidney Disease in the Community. Journal of the American Society of Nephrology. 19(6):1204-1211.

23. Wortmann R. (2002) Gout and hyperuricemia. Current Opinion in Rheumatology. 14(3):281-286.

24. Yoo T, Sung K, Shin H, Kim B, Kim B, Kang J. (2005) Relationship Between Serum Uric Acid Concentration and Insulin Resistance and Metabolic Syndrome. Circulation Journal. 69(8):928-933.

25. Zhou X, Matavelli L, Frohlich E. (2006) Uric acid: Its relationship to renal hemodynamics and the renal reninangiotensin system. Current Science Inc. 8(2):120-124.

26. Zhu J, Wang Y, Kong L, Yang C, Zhang X. (2004) Effects of Biota orientalis extract and its flavonoid constituents, quercetin and rutin on serum uric acid levels in oxonate-induced mice and xanthine dehydrogenase and xanthine oxidase activities in mouse liver. Journal of Ethnopharmacology. 93(1):133-140. 